Int. J. Electrochem. Sci., 14 (2019) 2265 - 2276

\title{
High Activity of Helical Carbon Nanotube supported Pd Nanoparticles for Ethanol Electro-oxidation in Alkaline Media
}

\author{
Beibei Wangl, Rongjing Cui ${ }^{2}$, Zhida Han $^{2}$, Yuhan Zhang ${ }^{l}$, Lin Wang ${ }^{l, *}$ \\ ${ }^{1}$ Department of Medical Chemistry, Hebei Medical University, Shijiazhuang 050017, China \\ ${ }^{2}$ School of Chemistry and Materials Engineering, Changshu Institute of Technology, Changshu \\ 215500, China \\ *E-mail: wanglin_hebmu@,163.com, 326640539@qq.com
}

doi: $10.20964 / 2019.03 .19$

Received: 9 October 2018 / Accepted: 28 December 2018 / Published: 7 February 2019

\begin{abstract}
Well-dispersed nanoparticles supported on carbon materials are synthesized successfully with a simple and facile method. Poly diallyldimethylammonium chloride (PDDA) functionalized helical carbon nanotubes (HCNTs) were used as the support material for the deposition of Pd nanoparticles by means of chemical reduction. The catalyst was characterized by scanning electron microscopy, transmission electron microscopy, energy dispersive X-ray spectroscopy, X-ray diffraction and X-ray photoelectron spectroscopy. The electrocatalytic activities of the prepared nanocomposites towards ethanol electrooxidation were studied by cyclic voltammetry and chronoamperometry. The results indicated that $\mathrm{Pd}$ nanoparticles, with an average size of $4 \mathrm{~nm}$, were uniformly dispersed onto the HCNTs/PDDA with a metal weight percentage of $20 \mathrm{wt}$. \%. The method provides a new vision for decentralization of the metal nanoparticles upon functionalized carbon supports for application as electrocatalyst in fuel cells.
\end{abstract}

Keywords: Pd nanoparticles, Helical carbon nanotubes, Ethanol oxidation

\section{$\underline{\text { FULL TEXT }}$}

(C) 2019 The Authors. Published by ESG (www.electrochemsci.org). This article is an open access article distributed under the terms and conditions of the Creative Commons Attribution license (http://creativecommons.org/licenses/by/4.0/). 